\title{
Effects of different agricultural wastes on the dissipation of PAHs and the PAH-degrading genes in a PAH-contaminated soil
}

\author{
Xuemei Han ${ }^{\text {a, b }}$, Hangwei Hu ${ }^{\text {c, **, }}$, Xiuzhen Shi ${ }^{c}$, Limei Zhang ${ }^{b}$, Jizheng He ${ }^{\text {b, c, * }}$ \\ a School of Resources and Environment, University of Jinan, Jinan, 250100, China \\ b State Key Laboratory of Urban and Regional Ecology, Research Center for Eco-Environmental Sciences, Chinese Academy of Sciences, Beijing, 100085, China \\ ${ }^{\mathrm{c}}$ Faculty of Veterinary and Agricultural Sciences, The University of Melbourne, Parkville, 3010, Victoria, Australia
}

\section{H I G H L I G H T S}

- Three agricultural wastes were used to a 90-day soil microcosm study.

- Agricultural wastes accelerated dissipation of the aged PAHs in soil microcosms.

- Agricultural wastes with lower C:N ratios eliminated the aged PAHs more quickly.

- Agricultural wastes significantly increased abundances of the PAH-degrading genes.

- Agricultural wastes obviously changed the community structure of PAH-degraders.

\section{A R T I C L E I N F O}

\section{Article history:}

Received 13 April 2016

Received in revised form

5 December 2016

Accepted 3 January 2017

Available online 5 January 2017

Handling Editor: Chang-Ping Yu

\section{Keywords:}

Polycyclic aromatic hydrocarbon

Agricultural waste

Bioremediation

qPCR

PAH-degrading gene

T-RFLP

\begin{abstract}
A B S T R A C T
Land application of agricultural wastes is considered as a promising bioremediation approach for cleaning up soils contaminated by aged polycyclic aromatic hydrocarbons (PAHs). However, it remains largely unknown about how microbial PAH-degraders, which play a key role in the biodegradation of soil PAHs, respond to the amendments of agricultural wastes. Here, a 90-day soil microcosm study was conducted to compare the effects of three agricultural wastes (i.e. WS, wheat stalk; MCSW, mushroom cultivation substrate waste; and CM, cow manure) on the dissipation of aged PAHs and the abundance and community structure of PAH-degrading microorganisms. The results showed that all the three agricultural wastes accelerated the dissipation of aged PAHs and significantly increased abundances of the bacterial 16S rRNA and PAH-degrading genes (i.e. pdo1 and nah). CM and MCSW with lower ratios of $\mathrm{C}: \mathrm{N}$ eliminated soil PAHs more efficiently than WS with a high ratio of C:N. Low molecular weight PAHs were dissipated more quickly than those with high molecular weight. Phylogenetic analysis revealed that all of the nah and C12O clones were affiliated within Betaproteobacteria and Gammaproteobacteria, and application of agricultural wastes significantly changed the community structure of the microorganisms harboring nah and $\mathrm{C} 12 \mathrm{O}$ genes, particularly in the CM treatment. Taken together, our findings suggest that the three tested agricultural wastes could accelerate the degradation of aged PAHs most likely through changing the abundances and community structure of microbial PAH degraders.
\end{abstract}

() 2017 Elsevier Ltd. All rights reserved.

\section{Introduction}

Polycyclic aromatic hydrocarbons (PAHs) are ubiquitous organic

\footnotetext{
* Corresponding author. State Key Laboratory of Urban and Regional Ecology, Research Center for Eco-Environmental Sciences, Chinese Academy of Sciences, Beijing, 100085, China.

** Corresponding author.

E-mail addresses: hang-wei.hu@unimelb.edu.au (H. Hu), jzhe@rcees.ac.cn (J. He).
}

pollutants characterized by high genotoxicity and carcinogenicity, and can enter and enrich in human body through the food chain (Johnsen et al., 2005; Peng et al., 2008; Niepceron et al., 2013). Environmental contamination caused by PAHs therefore poses a serious risk to public health and ecosystem safety (Johnsen et al., 2005; Peng et al., 2008). To date, 16 types of PAHs have been added into the blacklist of priority pollutants by the United States Environmental Protection Agency (USEPA) (Mackay et al., 1992). PAHs are mainly generated in the processes of coke production, petroleum refining and incomplete combustion of organic matters, 
and thus high levels of PAHs are frequently found in industrial sites (Johnsen et al., 2005). Aging of PAHs, that is, sequestration of them by soil aggregates, can appear during the contact with soils over time, which makes PAHs more resistant to degradation (Northcott and Jones, 2001; Luo et al., 2012). Therefore, remediation of soils polluted by aged PAHs has become a major issue for environmental scientists in recent years (Alcántara et al., 2008).

A wide variety of physical, chemical and biological approaches have been applied to remediation of soils polluted by organic chemical compounds (Pelaez et al., 2013). Compared to the high cost and potential secondary contamination incurred by physical and chemical methods, bioremediation, especially microbial remediation, is considered as a cost-effective option for cleaning up soils contaminated by PAHs (Jones et al., 2011; Pelaez et al., 2013; Vila et al., 2015). In general, microbial remediation plays an important role in eliminating PAHs from soils through two pathways, which are defined as biostimulation and bioaugmentation (Xu and Lu, 2010; Sayara et al., 2011). Biostimulation involves the modification of soil microbial habitats enabling soil resident bacteria to be more capable of degrading PAHs. For example, additions of organic substrates, oxygen or electron acceptors may enhance the activity of soil indigenous microbial populations to degrade PAHs in situ (Haritash and Kaushik, 2009; Nikolopoulou et al., 2013). By contrast, bioaugmentation is the introduction (or inoculation) of some specific competent $\mathrm{PAH}$-degrading microorganisms including natural microbial strains and genetically engineered variants to enhance the degradation of PAHs in the environment (Sayara et al., 2011; Festa et al., 2016). Numerous studies have reported effective PAH degradation through biostimulation and bioaugmentation strategies (Xu and Lu, 2010), whereas conflicting results existed that the introduced microbial strains could not significantly promote the degradation of PAHs owing to their poor adaptation to the new environmental conditions and the disadvantage in competing with indigenous microbial consortia (Lladó et al., 2013). For instance, Sayara et al. (2011) found that PAH degradation was significantly improved by using compost of the municipal solid waste as materials for biostimulation, while no significant effects were obtained by introducing white-rot fungi Trametes versicolor. Wu et al. (2016) compared bioaugmentation using Acinetobacter SZ-1 strain and biostimulation using $\left(\mathrm{NH}_{4}\right)_{2} \mathrm{SO}_{4}$ and $\mathrm{KH}_{2} \mathrm{PO}_{4}$ in a petroleum-contaminated soil. It was found that the dissipation of total petroleum hydrocarbons (TPH) and the amounts of cultivable TPH-, alkane- and PAH-degrading microorganisms were higher for biostimulation than for bioaugmentation. Therefore, it is essential to identify the substrates which could be added into soils to promote the degradation of PAHs through the bioremediation pathway.

Nutrient elements such as carbon, nitrogen and phosphorus are necessary for the growth of most microorganisms, and many studies have demonstrated that appropriate carbon sources can promote biodegradation of soil PAHs through introducing the cometabolic substrates (Sarkar et al., 2005; Lladó et al., 2009). Therefore, addition of organic substrates has been considered as a feasible remediation strategy in aged PAH-contaminated soils harboring abundant active microbial degraders (Antizar-Ladislao et al., 2005; Sayara et al., 2011). Teng et al. (2010) examined the bioremediation effects of three carbon sources (glucose, sodium succinate and starch) on an aged PAH-contaminated soil, and found that addition of carbon sources had a positive effect on the dissipation of phenanthrene and benzo( $a$ )pyrene as well as the cultivable bacterial and fungal counts. Antizar-Ladislao et al. (2005) reported that different ratios of soil/green waste had different effects on removal of PAHs in an aged coal tar soil. Although several studies have showed that microbial degradation of PAHs could be accelerated through adding organic substrates and inorganic nutrients to contaminated soils (Antizar-Ladislao et al., 2005; Wu et al., 2016), to our knowledge, these studies focused on the amounts of culturable PAH degraders which represent only a minor proportion of the total PAH-degrading populations (Singleton et al., 2005). To better understand how additive substrates influence the biodegradation of aged PAHs in soils, more efforts should be devoted to investigating the abundance and community structure of culture-independent PAH-degraders during the process of $\mathrm{PAH}$ degradation.

In the present study, three widespread agriculture wastes including wheat stalk (WS), mushroom cultivation substrate waste (MCSW) and cow manure (CM) were selected to promote the microbial degradation of aged PAHs in soil microcosms. Three targeted PAH-degrading genes including pdo1, C12O and nah, which encode the pyrene dioxygenase, catechol 1,2-dioxygenase and naphthalene dioxygenase, respectively, have been frequently detected in aged PAHs-polluted soils (Johnsen et al., 2006; Han et al., 2014). The elimination efficiency of various PAHs and the abundance and community composition of the three PAHdegrading genes were monitored during the incubation of the aged PAH-polluted soil treated with various agricultural wastes. We tested the following hypotheses: (i) the dissipation of aged PAHs would be promoted by input of agricultural wastes, owing to the nutrition supply, but the elimination efficiency would differ across treatments amended with different agricultural wastes based on the variance of introduced nutrient content and microbial consortia; (2) Addition of agricultural wastes would influence elimination of soil PAHs through altering the abundance and community structure of the PAH-degrading microorganisms.

\section{Materials and methods}

\subsection{Collection of agricultural wastes and physicochemical characterization}

Agricultural wastes including WS, MCSW and CM were taken from a farm in Tai'an, Shandong province, China. All the samples were passed through a $1.0 \mathrm{~mm}$ mesh, and air-dried for seven days. Total carbon (TC), total nitrogen (TN) and total sulfur (TS) in these agricultural wastes were measured on an element analyzer (Vario EL III, Elementar, Hanau, Germany). Dissolved organic matter (DOM) was extracted from each of agricultural wastes by Milli-Q water at ratios of $1: 20(\mathrm{w} / \mathrm{v}$, waste/water) for $\mathrm{WS}, 1: 40(\mathrm{w} / \mathrm{v})$ for MCSW, and 1:20 (w/v) for CM, respectively. The mixtures were shaken at $200 \mathrm{rpm}$ on a reciprocating shaker for $16 \mathrm{~h}$, centrifuged at $12,000 \mathrm{rpm}$ for $20 \mathrm{~min}$ at $4{ }^{\circ} \mathrm{C}$ and filtered through $0.45-\mu \mathrm{m}$ polycarbonate membranes (Millipore, Ireland). Dissolved organic carbon (DOC) in DOM extracts was measured using a TOC analyzer (LiquiTOC, Elementar Co., Hanau, Germany). The detailed information about the basic properties of these agricultural wastes is shown in Table 1.

\subsection{Soil collection and microcosm incubation}

The aged PAH-polluted soils were collected from a coke factory with six years of production history in Xintai $\left(35^{\circ} 54^{\prime} \mathrm{N}, 117^{\circ} 43^{\prime} \mathrm{E}\right)$, Shandong province, China. The collected soils were sieved through a 2-mm mesh, and divided into two portions. One portion was subject to measurement of basic physiochemical properties using conventional methods recommended by the Soil Science Society of China (Lu, 1999). TC, TN and TS of the soil samples were measured using an element analyzer (Vario EL III, Elementar). The detailed information about the soil basic characteristics is shown in Table 1. Another portion of soils was used to set up short-term laboratory microcosms in $480 \mathrm{ml}$ plastic vials containing $100 \mathrm{~g}$ of soils (oven 
Table 1

Basic properties of the PAH-contaminated soil and the three agricultural wastes.

\begin{tabular}{lllll}
\hline & Soil & WS & MCSW & CM \\
\hline $\mathrm{pH}$ & 7.34 & - & - & - \\
$\mathrm{H} 2 \mathrm{O}(\%)$ & 10.6 & - & - & - \\
$\mathrm{MWHC}(\%)$ & 44.5 & - & - & - \\
Sand (\%) & 48.3 & - & - & - \\
Silt (\%) & 46.8 & - & - & - \\
$\mathrm{Clay} \mathrm{( \% )}$ & 4.88 & - & - & - \\
$\mathrm{TC}\left(\mathrm{g} \mathrm{kg}^{-1}\right)$ & $38.8^{\mathrm{d}}$ & $367.2^{\mathrm{a}}$ & $274.0^{\mathrm{c}}$ & $281.0^{\mathrm{b}}$ \\
$\mathrm{TN}\left(\mathrm{g} \mathrm{kg}^{-1}\right)$ & $1.63^{\mathrm{d}}$ & $8.49^{\mathrm{c}}$ & $17.9^{\mathrm{b}}$ & $25.2^{\mathrm{a}}$ \\
$\mathrm{TS}\left(\mathrm{g} \mathrm{kg}^{-1}\right)$ & $1.65^{\mathrm{d}}$ & $6.06^{\mathrm{b}}$ & $9.05^{\mathrm{a}}$ & $4.91^{\mathrm{c}}$ \\
$\mathrm{C}: \mathrm{N} \mathrm{ratio}$ & $23.7^{\mathrm{b}}$ & $43.3^{\mathrm{a}}$ & $15.3^{\mathrm{c}}$ & $11.2^{\mathrm{d}}$ \\
DOC $\left(\mathrm{g} \mathrm{kg}^{-1}\right)$ & $0.15^{\mathrm{d}}$ & $18.2^{\mathrm{b}}$ & $29.2^{\mathrm{a}}$ & $13.7^{\mathrm{c}}$ \\
\hline
\end{tabular}

Notes: WS, wheat stalk; MCSW, mushroom cultivation substrate waste; CM, cow manure; MWHC, maximum water holding capacity. Different letters following the means $(n=3)$ in the same row indicate significant differences.

dry-weight equivalent), and sealed with air-permeable caps. Four sets of treatments were established in triplicate: the control treatment without addition of agricultural wastes (CK), and the treatments added with $6.25 \mathrm{~g}$ of WS, MCSW or CM agricultural wastes. Soil moisture content was adjusted to $60 \%$ of maximum water holding capacity (MWHC) and maintained constant through periodic replenishment of water. Soil microcosms were kept at $28^{\circ} \mathrm{C}$ in the dark for three months. Approximately $10 \mathrm{~g}$ of soils were sampled from each microcosm on days 5, 15, 30, 55 and 90 to determine the dynamics of 16 priority PAHs and microbial populations involved in $\mathrm{PAH}$ degradation.

\subsection{Measurement of the PAHs contents}

The 16 priority PAHs in soils were extracted using an ultrasonic method recommended by the USEPA (2000). The contents of 16 PAHs were determined on a GC-MS (HP7890-5975C, Agilent Technologies Inc., Wilmington, DE, USA) equipped with Agilent DB5MS Column $(30 \mathrm{~m} \times 0.25 \mathrm{~mm} \times 0.25 \mu \mathrm{m})$ with a flow rate of $1 \mathrm{ml} \mathrm{min}{ }^{-1}$ as previously described (Han et al., 2015).

A certified mixture containing 16 USEPA priority PAHs (AccuStandard, New Haven, CT, USA) and Hexamethylbenzene were used as the external and internal standards respectively (Han et al., 2015). PAHs were identified and quantified according to their retention time, target and qualifier ions, and a calibration curve was established with the ratio of external to internal standards. The recovery rate in the process of extraction and clean-up was determined using Phe-d10 spiked into the soils $24 \mathrm{~h}$ prior to extraction of PAHs.

\subsection{Soil DNA extraction and quantitative PCR ( $q P C R)$ assays}

The genomic DNA was extracted from $0.25 \mathrm{~g}$ of soil using the PowerSoil DNA Isolation Kit (MoBio Laboratories, Solana Beach, CA, USA) according to the manufacturer's instructions. The concentration and quality of the extracted DNA were measured with a ND1000 UV-Vis spectrophotometer (NanoDrop Technologies, Wilmington, DE, USA).

The bacterial 16S rRNA gene and the three PAH-degrading genes pdo1, nah and $C 120$ were amplified on an iCycler iQ 5 thermocycler (Bio-Rad Laboratories, Hercules, CA, USA). The primer pairs, probe and PCR conditions are listed in Table S1. Standard curves for qPCR assays were constructed as previously described (Han et al., 2015).

\subsection{Terminal-restriction fragment length polymorphism (T-RFLP) analysis}

Our previous studies in the same coke factory showed that all of the pdo1 gene sequences in clone libraries were affiliated into Mycobacterium (Han et al., 2014), and thus only the nah and C12O genes were analyzed with T-RFLP to determine the community structure of PAH degraders in the present study. The nah and $\mathrm{C12O}$ genes were amplified with the fluorescently labelled primers using the same procedure as that used in the qPCR analysis. The PCR products of the nah and $\mathrm{C12O}$ genes were purified with a Wizard SV gel and PCR Clean-up System (Promega). The nah gene PCR products were digested with the restriction endonucleases RsaI and AluI (TaKaRa) and the C12O gene PCR products with MspI (Promega) according to manufacturer's instructions. The resultant terminal restriction fragments (TRFs) were resolved using a Genetic Analyzer (3130XL, Applied Biosystems, Foster City, CA, USA) and analyzed with the GeneMapper 3.7 software. TRFs less than $50 \mathrm{bp}$ or with a percentage of less than $1 \%$ in the all T-RFs were discarded. The relative abundance of each TRF was calculated by dividing the peak area of the T-RF by that of total T-RFs.

\subsection{Construction of clone libraries and phylogenetic analysis}

The purified PCR products of the nah or C12O genes from the initial soil samples were used to construct the clone libraries with the pGEM-T Easy Vector system (Promega) following the manufacturer's instructions. The positive clones from the nah and $\mathrm{C} 12 \mathrm{O}$ clone libraries were selected for sequencing. Clone sequences sharing a $97 \%$ identity for the nah gene or an $85 \%$ identity for the C120 gene were classified into the same operational taxonomic unit (OTU) using the MOTHUR software (http://www.mothur.org/). The representative sequences of each OTU were subject to BLAST analysis against the GenBank database (http://blast.ncbi.nlm.nih. gov) and used to construct the phylogenetic trees using the neighbour-joining method with 1000 bootstrap replicates in MEGA version 5.0 (Tamura et al., 2011). The representative sequences of the nah and $\mathrm{C} 120$ gene clones used in phylogenetic trees have been deposited in the GenBank nucleotide sequence database, respectively.

\subsection{Statistical analyses}

The abundance of the bacterial 16S rRNA and PAH-degrading genes was log transformed prior to the statistical analysis. Twoway non-parametric analysis of variance (ANOVA) based on Scheirer-Ray-Hare test was used to assess the significance of the effects of different agricultural wastes, sampling time and their interactions on the abundance of targeted genes in SPSS 19.0. Oneway non-parametric ANOVA based on Kruskal-Wallis test was implemented to determine the significant differences in the content of PAHs or the abundance of bacterial 16S rRNA and PAHdegrading genes across different treatments at the same incubation time. Non-metric multidimensional scaling (NMDS) analysis was performed to display the Bray-Curtis dissimilarity matrices based on the relative abundance of the nah and C12O gene TRFs across different treatments. Additionally, a permutational multivariate analysis of variance (PERMANOVA) test was performed to compare whether the T-RFLP profiles of the nah and C12O genes in different treatments were statistically different, by using the "adonis" function of the "vegan" package in R platform with 999 permutations. The difference at the level of $P<0.05$ was accepted to be statistically significant.

\section{Results}

\subsection{Properties of the soil and agricultural wastes}

The soil is classified as neutral sandy loam according to the soil 
taxonomy of US system. The contents of TC, TN, TS and DOC in agricultural wastes ranged from 274.0 to $367.2 \mathrm{~g} \mathrm{~kg}^{-1}$, 8.49-25.2 $\mathrm{g} \mathrm{kg}^{-1}, 4.91-9.05 \mathrm{mg} \mathrm{kg}$, and $13.7-29.2 \mathrm{~g} \mathrm{~kg}^{-1}$, respectively, which were significantly higher than those in soil samples (Table 1). The contents of these chemical parameters were also significantly different across WS, MCSW and CM. The C:N ratio of the collected soil was 23.7 which was significantly lower than that of WS but higher than those of CM and MCSW.

\subsection{Impacts of agricultural waste amendment on the degradation of PAHs}

The recovery rates of standard Phe-d10 were from $78.3 \%$ to 97.6\% and did not significantly change over the incubation time, indicating the validity of the extraction and purifying method. The 16 types of PAHs were divided into five groups based on the numbers of aromatic ring. The initial content of total PAHs in the soil was $36.1 \mathrm{mg} \mathrm{kg}^{-1}$ dry soil, with a high proportion of 4-ring PAHs comprising $41.7 \%$ of total PAHs. The changes in the absolute contents of residual PAHs in soil microcosms at each sampling time are illustrated in Fig. 1. The soils were taken from the sites with six years of coking production history, and therefore the PAHs in the soils had been considered as the aged ones at the start of microcosm establishment. Here, aging of PAHs over the short incubation time was neglected, and the differences of residual PAHs were only analyzed in different treatments at the same incubation time. No significant decline in the PAHs content was observed for all the treatments compared with $\mathrm{CK}$ at the first three sampling points. However, a significant positive effect of agricultural wastes on the degradation of PAHs was observed in the later period of incubation. There were significantly less residual PAHs in MCSW and CM on day 55 compared with CK. At the end of incubation, $24.4 \%$ of total PAHs relative to their initial content in the collected soils were eliminated in $\mathrm{CK}$, while a greater removal rate of $33.3-40.4 \%$ was achieved in treatments added with agricultural wastes (Table 2). Furthermore, the PAHs with different numbers of aromatic rings differed in their

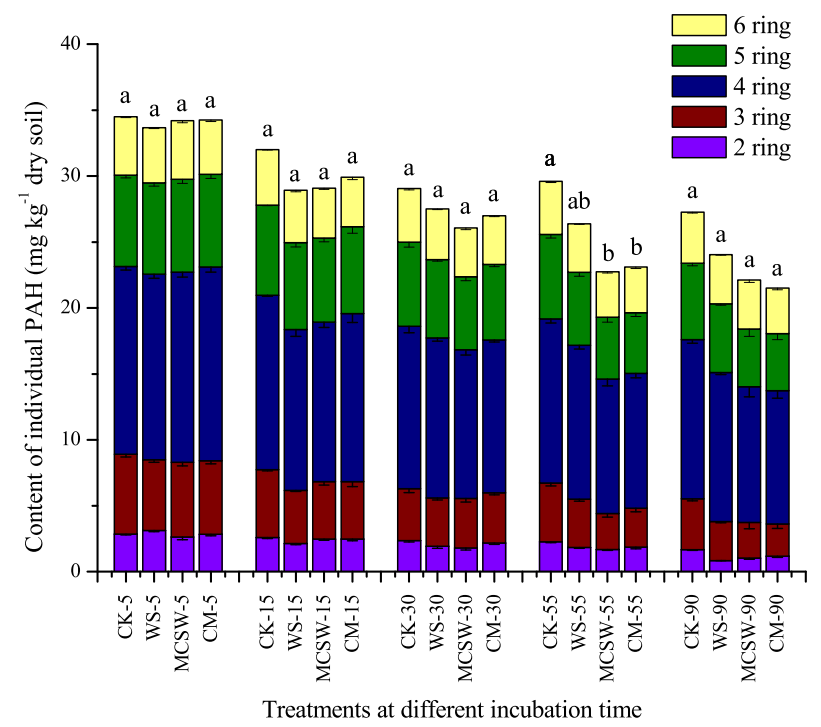

Fig. 1. Changes in the absolute contents of PAHs in soil microcosms at different incubation periods. CK, WS, MCSW and CM represent the control and the treatments with wheat stalk, mushroom cultivation substrate waste and cow manure, respectively. $-5,-15,-30,-55$ and -90 mean the incubation periods of $5,15,30,55$ and 90 days, respectively. Error bars indicate standard deviations $(n=3)$. Different letters in the same column indicate significant differences of the total PAH contents across different treatments at the same incubation time. degradation rates. The PAHs with low molecular weight (LMW) had higher degradation rates of $40.7-61.2 \%$, compared to $18.7-33.1 \%$ for those with high molecular weight (HMW) in all soil microcosms. However, dissipation of the 5-ring PAHs was faster than the 4-ring PAHs when added with agricultural wastes.

\subsection{Impacts of agricultural waste amendment on the abundances of the 16S rRNA, pdo1, C120 and nah genes}

The initial absolute abundances of the 16S rRNA, pdo1, C120 and nah genes in soil microcosms were $4.66 \times 10^{10}, 3.13 \times 10^{9}$, $5.06 \times 10^{6}$ and $2.10 \times 10^{6}$ copies $g^{-1}$ dry soil, respectively. The log transformed copy numbers of these genes during the incubation period are illustrated in Fig. 2. The non-parametric two-way ANOVA analysis showed that the treatments with agricultural wastes exerted significant influence on the abundance of all targeted genes. The incubation time and its interaction with treatment had also significant effects on the abundances of some detected genes (Table S2).

The non-parametric one-way ANOVA was further implemented to determine the effects of different agricultural wastes on the abundance of the targeted genes at the same incubation time. Overall, the added agricultural wastes had significant and positive effects on the abundance of some targeted genes, but these genes showed different patterns responding to the amendment of agricultural wastes. The bacterial 16S rRNA gene abundance was significantly higher in CM and MCSW treatments than that in CK during most of the incubation period. The pdo1 gene was more abundant in CM and MCSW treatments than CK after 5 days of incubation. The $\mathrm{C} 120$ gene abundance did not significantly increase in all treatments during the whole incubation period. Addition of MCSW greatly enhanced the nah gene abundance compared to CK on days 15, 55 and 90 of incubation (Fig. 2).

\subsection{Community structure of the nah and $\mathrm{C} 12 \mathrm{O}$ genes in soil microcosms}

The T-RFLP analysis of the nah gene yielded four distinct TRFs, of which TRF-325 was the most dominant phylotype with a proportion ranging from 55.8 to $80.4 \%$ (Fig. 3a). In general, amendment of the three agricultural wastes obviously increased the relative abundance of TRF-325 but decreased the TRF-221 abundance during the early and middle stages of incubation. Similarly, the relative abundance of TRF-260 in WS and MCSW was observed to increase in the early period of incubation. No significant effects of agricultural wastes on the patterns of TRF-92 could be observed. The PERMANOVA analysis showed that T-RFLP profiles of the nah gene were significantly different across the different treatments (Pseudo- $F=24.7, P<0.001$ ). The NMDS ordination showed that the

Table 2

The proportions (\%) of soil PAHs with different rings degraded at the end of incubation relative to their initial content in soils collected from the coke factory.

\begin{tabular}{lllll}
\hline & CK & WS & MCSW & CM \\
\hline 2-ring PAHs & 49.2 & 74.3 & 62.3 & 64.0 \\
3-ring PAHs & 36.1 & 51.2 & 55.8 & 59.7 \\
4-ring PAHs & 19.8 & 24.9 & 31.6 & 32.7 \\
5-ring PAHs & 18.4 & 26.5 & 38.0 & 39.2 \\
6-ring PAHs & 15.8 & 18.8 & 19.2 & 24.9 \\
LMW PAHs & 40.7 & 59.3 & 60.2 & 61.2 \\
HMW PAHs & 18.7 & 24.3 & 31.2 & 33.1 \\
total PAHs & 24.4 & 33.3 & 38.7 & 40.4 \\
\hline
\end{tabular}

CK, WS, MCSW and CM represent the control and the treatments with wheat stalk, mushroom cultivation substrate waste and cow manure, respectively. Data shown represent the mean values of three replicates. 

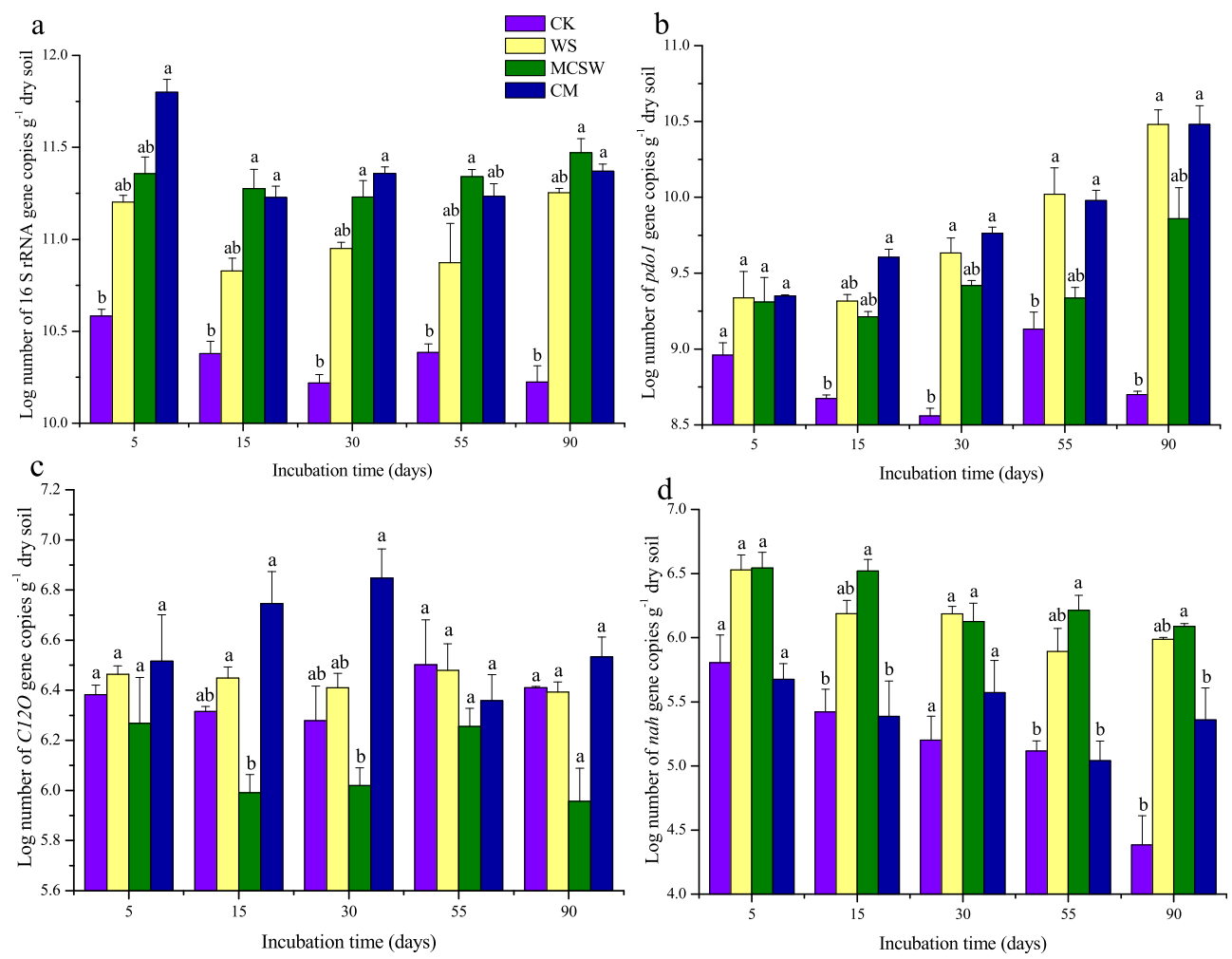

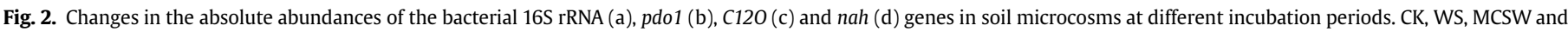

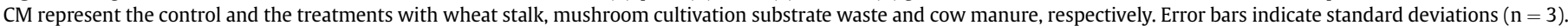

treatments with agricultural wastes had a clear divergence from CK, and the $\mathrm{CM}$ treatment was also obviously separated from other treatments (Fig. 4a).

A total of 10 TRFs were obtained for the $C 120$ gene (Fig. 3b). TRF139 was the most prevalent phylotype with a proportion ranging from 11.9 to $83.7 \%$. TRF-122, TRF-157, TRF-86, TRF-83 and TRF-210 were also abundant phylotypes. The proportion of TRF-139 markedly increased, while TRF-86 and TRF-122 obviously declined in CM compared to CK. The percentages of TRF-157, TRF-210 and TRF-83 showed a rising trend in WS and MCSW. The PERMANOVA analysis showed that T-RFLP patterns of the C120 gene were significantly distinct across different treatments (Pseudo- $F=25.2$, $P<0.001)$. The NMDS analysis showed a divergence of treatments with agricultural wastes from CK (Fig. 4b). In particular, the T-RFLP profile of the $\mathrm{C} 12 \mathrm{O}$ gene in $\mathrm{CM}$ obviously separated from other treatments throughout the whole incubation time.

\subsection{Phylogeny of the nah and C120 genes in soil microcosms}

A total of 54 sequences from the nah gene clone library were assigned into 11 OTUs. The representative sequences from each OTU, which were used to construct the phylogenetic tree, contained all TRFs types. All clones of the nah gene were affiliated within Betaproteobacteria (59.3\%) and Gammaproteobacteria (40.7\%) (Fig. 5a). The clones of TRF-325 and TRF-92 were classified into Betaproteobacteria, while those of TRF-260 and TRF-221 were clustered into Gammaproteobacteria.

A total of 143 sequences from the $C 120$ gene clone library were assigned into 19 OTUs, and covered all TRFs types. The phylogenetic tree showed that all of the $\mathrm{C} 120$ clones were grouped into Gammaproteobacteria (66.4\%) and Betaproteobacteria (33.6\%) (Fig. 5b). For the dominant TRF-139, 86 TRFs were found in Gammaproteobacteria and two TRFs in Betaproteobacteria. TRF-210 only emerged in Gammaproteobacteria, while the TRF-122, -92, -157, -194, -97 and -110 existed in Betaproteobacteria. Five of seven TRF-86 clones were classified into Gammaproteobacteria.

\section{Discussion}

\subsection{Impacts of agricultural wastes on the degradation rates of PAHs}

Biostimulation is one of the most widely used microbial strategies to remove PAHs from soils (Sayara et al., 2011). In this study, we found that addition of three common agricultural wastes enhanced the dissipation of PAHs in soil microcosms, but they had different removal efficiencies of total PAHs. Although carbon source was considered as a major nutrient for bacterial growth, the C:N ratio was also suggested to be an important factor affecting the growth of soil microorganisms (Zhou and Crawford, 1995). Previous studies have demonstrated that the optimum ratio of soil C:N for microbial growth was around 10 (Teng et al., 2010). In this study, the C: $\mathrm{N}$ ratio of the soil was 23.7, and addition of WS with a high $\mathrm{C}: \mathrm{N}$ ratio (43.3) would further elevate the $\mathrm{C}: \mathrm{N}$ ratios in the soil microcosms. By contrast, the introduced $\mathrm{CM}$ (with a $\mathrm{C}: \mathrm{N}$ ratio of 11.2) and MCSW (with a C:N ratio of 15.3 ) would strongly reduce the soil $\mathrm{C}: \mathrm{N}$ ratio, and it might partially explain the observation that addition of CM and MCSW significantly accelerated the dissipation of soil PAHs on day 55 compared to the control. Therefore, we supposed that an appropriate $\mathrm{C}: \mathrm{N}$ ratio might play a crucial role in determining the effects of agricultural wastes on the microbial degradation of PAHs especially under nitrogen-depleted conditions. On the other hand, input of carbon-rich materials could promote the adsorption of soil PAHs, which was assumed to be an important factor impeding microbial bioremediation of the aged PAHs in soil (Kobayashi et al., 2009). On the contrary, nutrient sources enriched in nitrogen have been known to enhance the 

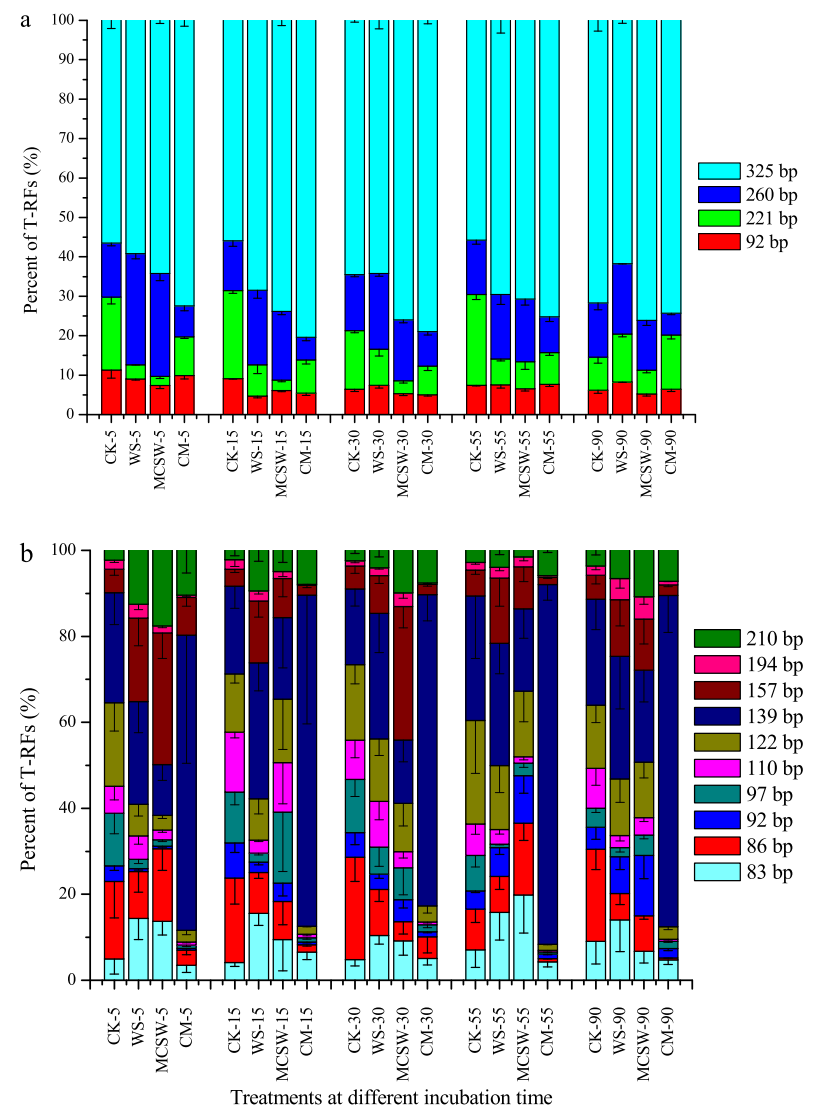

Fig. 3. T-RFLP patterns of the nah (a) and $\mathrm{C} 120$ (b) genes across different treatments in soil microcosms at different incubation periods. CK, WS, MCSW and CM represent the control and the treatments with wheat stalk, mushroom cultivation substrate waste and cow manure, respectively. $-5,-15,-30,-55$ and -90 mean the incubation periods of $5,15,30,55$ and 90 days. Error bars indicate standard deviations $(n=3)$.

bioavailability of aged PAHs (Teng et al., 2010; Pelaez et al., 2013). Therefore, these findings together with our study suggested that substrates with appropriate $\mathrm{C}: \mathrm{N}$ ratios could facilitate the remediation of soils contaminated by aged PAHs. Except for C:N ratio, microbial degraders may be affected by introduced metals and trace elements, thus effects of the diverse constituents on PAH dissipation should be fully considered when selecting feasible biostimulation materials.

In this study, we observed that HMW PAHs were degraded more slowly than LMW PAHs (Table 2). It is well known that the aqueous solubility and bioavailability of PAHs declines with the increasing numbers of aromatic rings of PAHs. As a consequence, HMW PAHs were more resistant to microbial degradation than the LMW PAHs (Peng et al., 2008). In the control, the dissipation of PAHs with different aromatic rings was completely in accordance with the degradation rule. However, the 5-ring PAHs were dissipated faster than the 4-ring PAHs in the treatments with agricultural wastes, which is in line with previous studies (Potin et al., 2004; Li et al., 2012). It was speculated that the faster dissipation of 5-ring PAHs than 4-ring PAHs might be attributed to the added agricultural wastes. Although PAHs with above five aromatic rings were highly recalcitrant under natural conditions, they could be biodegraded efficiently where co-metabolic substrate existed after addition of agricultural wastes (Johnsen et al., 2005; Haritash and Kaushik, 2009). In addition, some studies have demonstrated that Mycobacterium had a good catabolic capacity towards degrading PAHs up to five benzene rings due to their lipophilic surfaces and biosurfactant production (McClellan et al., 2002; Bogan et al., 2003). Therefore, the
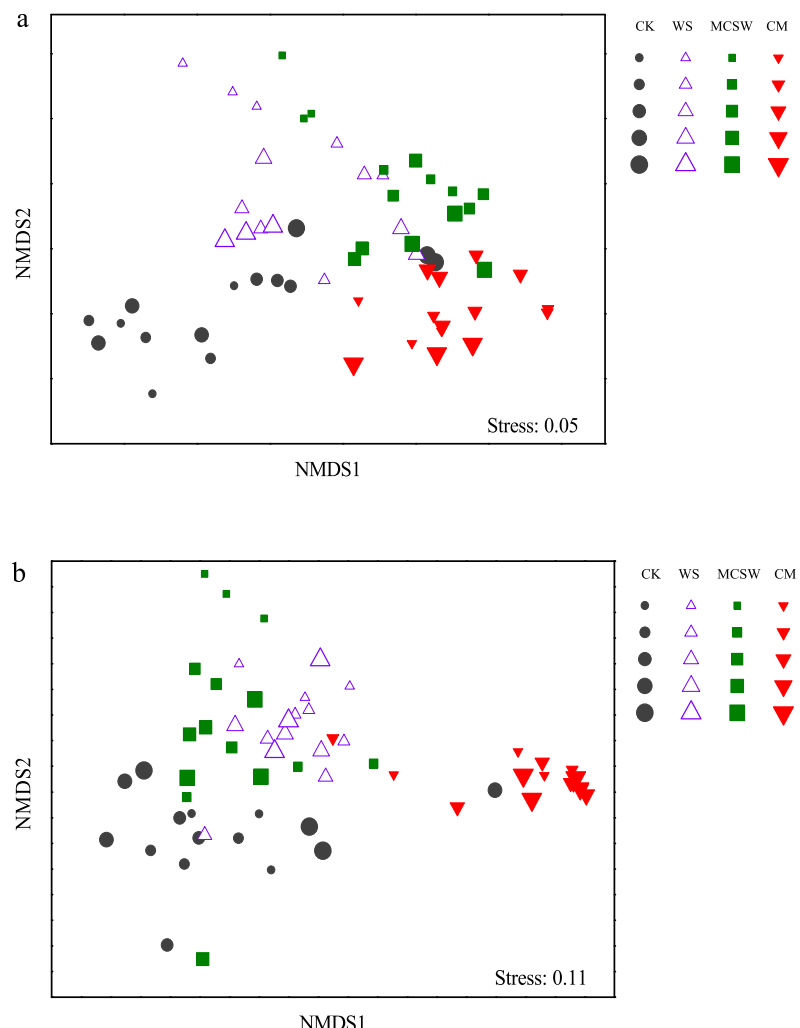

Fig. 4. NMDS ordinations based on the Bray-Curtis similarity indices of the T-RFLP data of the nah (a) and C12O (b) genes across different treatments. CK, WS, MCSW and CM represent the control and the treatments with wheat stalk, mushroom cultivation substrate waste and cow manure, respectively. $-5,-15,-30,-55$ and -90 mean the incubation periods of $5,15,30,55$ and 90 days.

abundant and ever-increasing Mycobacterium harboring the pdo1 gene during the incubation might play an important role in eliminating 5-ring PAHs in the treatments with agricultural wastes.

\subsection{Impacts of agricultural wastes on the abundances of PAH- degrading genes}

Irrespective of the nature and chemical structure of the different types of PAHs, the degradation of PAHs is assumed to be mainly dependent on the abundance and composition of microbial populations with the capacity of degrading PAHs (Haritash and Kaushik, 2009). In this study, the increased abundance of the bacterial 16S rRNA and the PAH-degrading genes ( $p d o 1$ and nah) was in coincidence with the faster attenuation of PAHs in soil microcosms treated with agricultural wastes relative to the control, which supported the assumption that agricultural wastes could improve the biodegradation of PAHs through increasing the abundance of PAH-degrading populations in soils. Previous studies have identified some important PAH-degrading microorganisms such as Mycobacterium harboring the pdo1 gene and Betaproteobacteria and Gammaproteobacteria carrying the nah gene (Johnsen et al., 2006; Han et al., 2015). Our results found that addition of agricultural wastes could impose positive effects on the abundances of these genes. It might be attributed to the nutritional components (e.g. carbon, nitrogen, and phosphorous etc.) constantly provided for soil microbes by the slow-releasing agricultural wastes (Teng et al., 2010; Pelaez et al., 2013). Several previous studies also demonstrated that supply of carbon, nitrogen and phosphorous sources could enhance the proliferation of soil microorganisms and hydrocarbon degraders (Vinas et al., 2005; Teng et al., 2010; Pelaez 

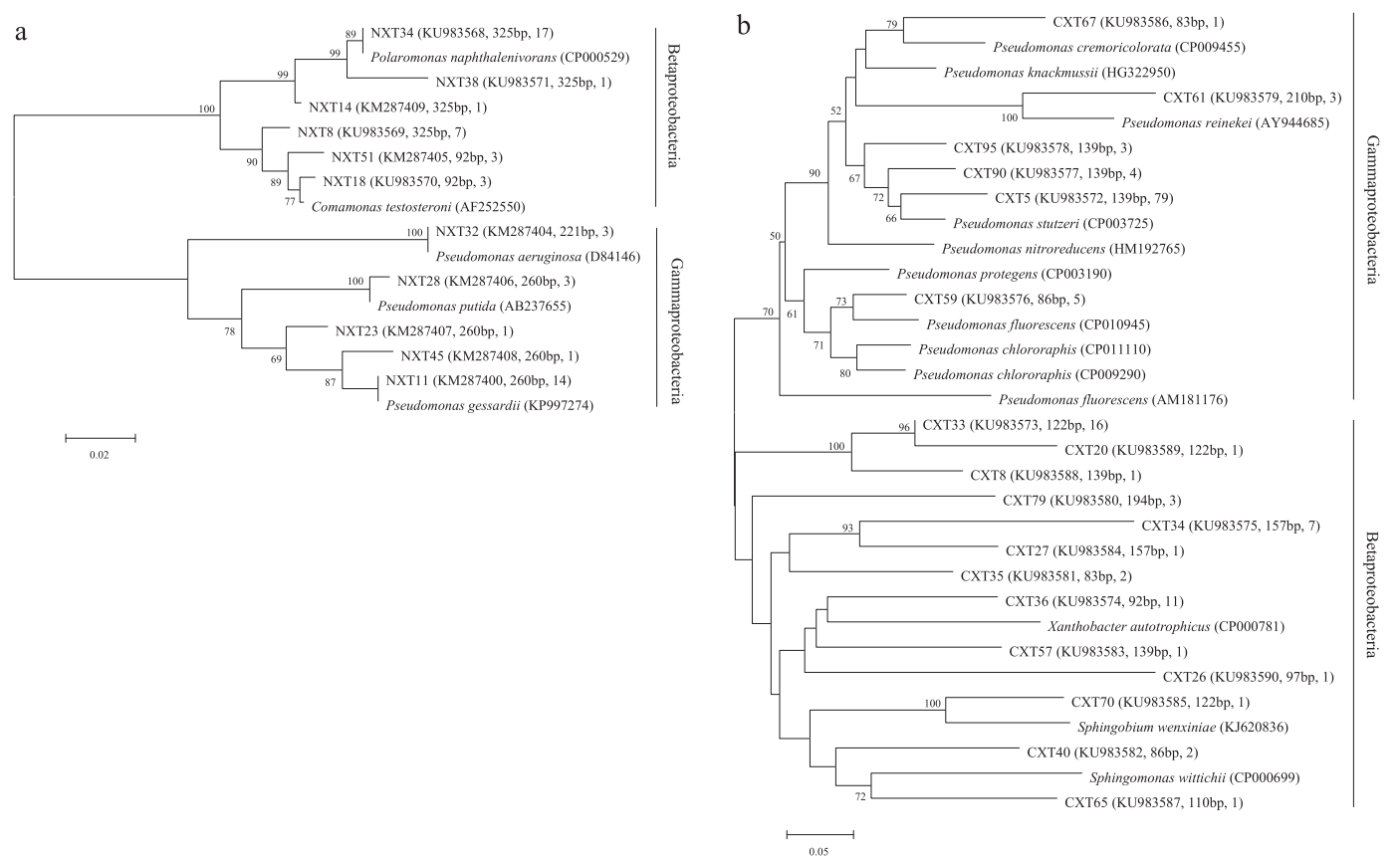

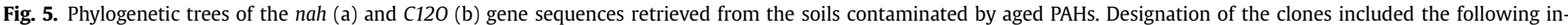

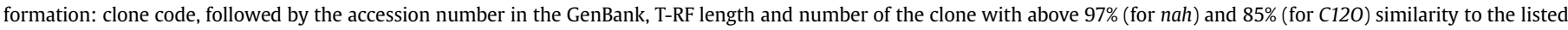
representative sequence in the parentheses. Bootstrap values ( $>50 \%$ ) were indicated on nodes. The scale bars represent $2 \%$ (a) and $5 \%$ (b) estimated sequence divergences.

et al., 2013). Aside from the biostimulation caused by nutrient input, agricultural wastes contain microbial populations, and thus might also have an effect of bioaugmentation on soil microbial populations (Li et al., 2012).

\subsection{Impacts of agricultural wastes on the community structure of PAH-degraders}

In this study, all the nah and $\mathrm{C} 120$ clones were affiliated within Betaproteobacteria and Gammaproteobacteria, which indicated that these two bacterial taxa are potential important PAH degraders in soils (Lors et al., 2010; Niepceron et al., 2013). It was observed that the CM treatment exerted a remarkable influence on the T-RFLP patterns of PAH degraders. As for the T-RFLP profile of the nah gene, some TRFs such as TRF-260 affiliated into Gammaproteobacteria were apparently different from the control. The T-RFLP pattern of the $C 120$ gene also obviously showed that the CM treatment was always different from other treatments. In addition, various agricultural wastes imposed discrepant influences on the T-RFLP profiles of the nah and $\mathrm{C} 120$ genes. The CM treatment seemed to have a more persistent effect on community structures of the nah and C120 genes while those in WS and MCSW had a trend of recovery towards the control in the later incubation time. It indicated that addition of agricultural wastes had a significant effect on community components of the nah and $\mathrm{C} 120$ genes, and various agricultural wastes usually imposed different influences on the community structure of the PAH-degrading genes (Han et al., 2015). Li et al. (2012) found similar results that the community structure of bacteria and fungi showed different responses to addition of mushroom cultivation substrate in PAH-contaminated soils. Overall, the abundances of the PAH-degrading genes were not significantly higher in CM than those in other treatments in this study. However, the PAHs in CM were eliminated more quickly than other treatments. It was probably due to the notable changes in the community structure of PAH degraders in CM. In contrast to WS with high content of refractory hemicellulose, cellulose and lignin
(Zhang et al., 2016) and MCSW with probably poor fungal colonization (Li et al., 2012), CM might harbor more abundant active microorganisms (Girija et al., 2013) and had a significant influence on microbial consortia in soil. In summary, although various agricultural wastes affected PAH-degrading genes in different ways, our results indicated that external stimuli produced by agricultural wastes enhance the microbial degradation of PAHs in soils through not only enhancing the abundance but also altering the community composition of microbial PAH degraders.

\section{Conclusions}

This study provided evidence for the modulation of agricultural wastes on dissipation of aged PAHs most likely through influencing the abundance and community structure of soil microbial degraders. We found that all treatments amended with agricultural wastes enhanced the elimination of soil PAHs, and the agricultural wastes with low ratios of $\mathrm{C}: \mathrm{N}$ could more effectively enhance the attenuation of PAHs than that with relatively high ratios of C:N. The addition of agricultural wastes significantly improved abundances of the PAH-degrading genes (i.e. pdo1 and nah) and bacterial $16 \mathrm{~S}$ rRNA gene, and changed the community structure of the nah and C120 genes. Our findings contribute to the understanding of how the bioremediation with agricultural wastes regulate the depletion of aged PAHs from polluted soil environments.

\section{Acknowledgements}

This study was financially supported by Natural Science Foundation of China (41301567) and Key Research and Development Program of Shandong Province (2015GSF117033).

\section{Appendix A. Supplementary data}

Supplementary data related to this article can be found at http:// dx.doi.org/10.1016/j.chemosphere.2017.01.012. 


\section{References}

Alcántara, M.T., Gómez, J., Pazos, M., Sanromán, M.A., 2008. Combined treatment of PAHs contaminated soils using the sequence extraction with surfactantelectrochemical degradation. Chemosphere 70, 1438-1444.

Antizar-Ladislao, B., Lopez-Real, J., Beck, A.J., 2005. In-vessel compostingbioremediation of aged coal tar soil: effect of temperature and soil/green waste amendment ratio. Environ. Int. 31, 173-178.

Bogan, B.W., Lahner, L.M., Sullivan, W.R., Paterek, J.R., 2003. Degradation of polycyclic aromatic and straight-chain aliphatic hydrocarbons by a strain of $\mathrm{Myco-}$ bacterium austroafricanum. J. Appl. Microbiol. 94, 230-239.

Festa, S., Coppotelli, B.M., Morelli, I.S., 2016. Comparative bioaugmentation with a consortium and a single strain in a phenanthrene-contaminated soil: impact on the bacterial community and biodegradation. Appl. Soil Ecol. 98, 8-19.

Girija, D., Deepa, K., Xavier, F., Antony, I., Shidhi, P.R., 2013. Analysis of cow dung microbiota-A metagenomic approach. Indian J. Biotechnol. 12 (3), 372-378.

Han, X.M., Liu, Y.R., Zhang, L.M., He, J.Z., 2015. Insight into the modulation of dissolved organic matter on microbial remediation of PAH-contaminated soils. Microb. Ecol. 70, 400-410.

Han, X.M., Liu, Y.R., Zheng, Y.M., Zhang, X.X., He, J.Z., 2014. Response of bacteria pdo1, nah and $\mathrm{C} 120$ genes to aged soil PAH pollution in a coke factory area. Environ. Sci. Pollut. Res. 21, 9754-9763.

Haritash, A.K., Kaushik, C.P., 2009. Biodegradation aspects of polycyclic aromatic hydrocarbons (PAHs), a review. J. Hazard. Mater. 169, 1-15.

Johnsen, A.R., de Lipthay, J.R., Sørensen, S.J., Ekelund, F., Christensen, P. Andersen, O., Karlson, U., Jacobsen, C.S., 2006. Microbial degradation of street dust PAHs in microcosms simulating diffuse pollution of urban soil. Environ. Microbiol. 8, 535-545.

Johnsen, A.R., Wick, L.Y., Harms, H., 2005. Principles of microbial PAH-degradation in soil. Environ. Pollut. 133, 71-84.

Jones, M.D., Crandell, D.W., Singleton, D.R., Aitken, M.D., 2011. Stable-isotope probing of the polycyclic aromatic hydrocarbon-degrading bacterial guild in a contaminated soil. Environ. Microbiol. 13, 2623-2632.

Kobayashi, T., Murai, Y., Tatsumi, K., Iimura, Y., 2009. Biodegradation of polycyclic aromatic hydrocarbons by Sphingomonas sp. enhanced by water-extractable organic matter from manure compost. Sci. Total Environ. 407, 5805-5810.

Li, X.Z., Wu, Y.C., Lin, X.G., Zhang, J., Zeng, J., 2012. Dissipation of polycyclic aromatic hydrocarbons (PAHs) in soil microcosms amended with mushroom cultivation substrate. Soil Biol. Biochem. 47, 191-197.

Lladó, S., Gràcia, E., Solanas, A.M., Viñas, M., 2013. Fungal and bacterial microbial community assessment during bioremediation assays in an aged creosotepolluted soil. Soil Biol. Biochem. 67, 114-123.

Lladó, S., Jiménez, N., Viñas, M., Solanas, A.M., 2009. Microbial populations related to $\mathrm{PAH}$ biodegradation in an aged biostimulated creosote-contaminated soil. Biodegradation 20, 593-601.

Lors, C., Ryngaert, A., Périé, F., Diels, L., Damidot, D., 2010. Evolution of bacterial community during bioremediation of PAHs in a coal tar contaminated soil Chemosphere 81, 1263-1271.

Lu, R.K., 1999. Analysis Methods of Soil Agrichemistry. China Agricultural Science and Technology Press, Beijing.

Luo, L., Lin, S., Huang, H.L., Zhang, S.Z., 2012. Relationships between aging of PAHs and soil properties. Environ. Pollut. 170, 177-182.

Mackay, D., Shiu, W.Y., Ma, K.C., 1992. Illustrated Handbook of Physical-chemical Properties and Environmental Fate for Organic Chemicals, vol. 2. Lewis Publishers, Michigan.

McClellan, S.L., Warshawsky, D., Shann, J.R., 2002. The effect of polycyclic aromatic hydrocarbons on the degradation of benzo[a]pyrene by Mycobacterium sp. Strain RJGII-135. Environ. Toxicol. Chem. 21, 253-259.
Niepceron, M., Martin-Laurent, F., Crampon, M., Portet-Koltalo, F., AkpaVinceslas, M., Legras, M., Bru, D., Bureau, F., Bodilis, J. 2013. GammaProteobacteria as a potential bioindicator of a multiple contamination by polycyclic aromatic hydrocarbons (PAHs) in agricultural soils. Environ. Pollut. 180, 199-205.

Nikolopoulou, M., Pasadakis, N., Norf, H., Kalogerakis, N., 2013. Enhanced ex situ bioremediation of crude oil contaminated beach sand by supplementation with nutrients and rhamnolipids. Mar. Pollut. Bull. 77, 37-44.

Northcott, G.L., Jones, K.C., 2001. Partitioning, extractability, and formation of nonextractable PAH residues in soil. 1. Compound differences in aging and sequestration. Environ. Sci. Technol. 35, 1103-1110.

Pelaez, A.I., Lores, I., Sotres, A., Mendez-Garcia, C., Fernandez-Velarde, C., Santos, J.A., Gallego, J.L.R., Sanchez, J., 2013. Design and field-scale implementation of an "on site" bioremediation treatment in PAH-polluted soil. Environ. Pollut. 181, 190-199.

Peng, R.H., Xiong, A.S., Xue, Y., Fu, X.Y., Gao, F., Zhao, W., Tian, Y.S., Yao, O.H., 2008. Microbial biodegradation of polyaromatic hydrocarbons. FEMS Microbiol. Rev. 32, 927-955.

Potin, O., Rafin, C., Veignie, E., 2004. Bioremediation of an aged polycyclic aromatic hydrocarbons (PAHs)-contaminated soil by filamentous fungi isolated from the soil. Int. Biodeter. Biodegr. 54, 45-52.

Sarkar, D., Ferguson, M., Datta, R., Birnbaum, S., 2005. Bioremediation of petroleum hydrocarbons in contaminated soils: comparison of biosolids addition, carbon supplementation, and monitored natural attenuation. Environ. Pollut. 136, $187-195$.

Sayara, T., Borràs, E., Caminal, G., Sarrà, M., Sánchez, A., 2011. Bioremediation of PAHs-contaminated soil through composting: influence of bioaugmentation and biostimulation on contaminant biodegradation. Int. Biodeter. Biodegr. 65, 859-865.

Singleton, D.R. Powell, S.N., Sangaiah, R., Gold, A., Ball, L.M., Aitken, M.D., 2005 Stable-isotope probing of bacteria capable of degrading salicylate, naphthalene, or phenanthrene in a bioreactor treating contaminated soil. Appl. Environ. Microbiol. 71, 1202-1209.

Tamura, K. Peterson, D. Stecher, G. Nei, M. Kumar, S, 2011. MEGA5: molecular evolutionary genetics analysis using maximum likelihood, evolutionary distance, and maximum parsimony methods. Mol. Biol. Evol. 28, 2731-2739.

Teng, Y., Luo, Y., Ping, L., Zou, D., Li, Z., Christie, P., 2010. Effects of soil amendment with different carbon sources and other factors on the bioremediation of an aged PAH-contaminated soil. Biodegradation 21, 167-178.

USEPA, 2000. Method 3550C, Test Methods for Evaluating Solid Waste. EPA SW-846, third ed. US Government Print Office, Washington.

Vila, J., Tauler, M., Grifoll, M., 2015. Bacterial PAH degradation in marine and terrestrial habitats. Curr. Opin. Biotech. 33, 95-102.

Vinas, M., Sabate, J., Espuny, M., Solanas, M., 2005. Bacterial community dynamics and polycyclic aromatic hydrocarbon degradation during bioremediation of heavily creosote-contaminated soil. Appl. Environ. Microbiol. 71, 7008-7018.

Wu, M.L., Dick, W.A., Li, W., Wang, X.C., Yang, Q., Wang, T.T., Xu, L.M., Zhang, M.H., Chen, L.M. 2016. Bioaugmentation and biostimulation of hydrocarbon degradation and the microbial community in a petroleum-contaminated soil. Int. Biodeter. Biodegr. 107, 158-164.

Xu, Y.H., Lu, M., 2010. Bioremediation of crude oil-contaminated soil: comparison of different biostimulation and bioaugmentation treatments. J. Hazard. Mater. 183, 395-401.

Zhang, L.L., Jia, Y.Y., Zhang, X.M., Feng, X.H., Wu, J.J., Wang, L.S., Chen, G.J., 2016. Wheat straw: an inefficient substrate for rapid natural lignocellulosic composting. Bioresour. Technol. http://dx.doi.org/10.1016/j.biortech.2016.03.004.

Zhou, E.N., Crawford, R.L., 1995. Effects of oxygen, nitrogen, and temperature on gasoline biodegradation in soil. Biodegradation 6 (2), 127-140. 